\title{
Información para los autores
}

Ciencia y Desarrollo es una revista multidisciplinaria de acceso abierto en línea e impresa, revisada por pares, con arbitraje externo ciego, previa evaluación del Comité Científico y del Comité editorial. La revista, tiene como objetivo publicar los productos de la investigación de los docentes de la Universidad Alas Peruanas y de otras instituciones científicas, orientados al mundo académico especializado. Está dedicada a promover el intercambio y la discusión de todas las áreas de investigación; pero en especial las que corresponden a las líneas de ingenierías, salud, educación, comercio, ambiental, agropecuarias y Gestión del Territorio, en forma de artículos originales, revisión de artículos, reporte de casos, artículos de avance tecnológico y ensayos.

Los artículos enviados para su publicación que presenten resultados de estudios aplicados en seres humanos, deben cumplir con las pautas de la Declaración de Helsinki. Los estudios con animales y de medio ambiente, deberán incluir una declaración sobre la aprobación ética de los mismos. Así mismo, se deberá remitir al Comité Científico, una carta de presentación que incluya la siguiente información: el objetivo de la investigación, la declaración de cualquier conflicto de interés del autor (es) y la confirmación de que todos los autores aprobaron el manuscrito para su envío, así como la confirmación de que el contenido del manuscrito no se ha publicado o enviado para su publicación en otra revista. Derechos de autor

Los derechos de autor de cualquier articulo abierto o impreso, son conservados por el Comité Editorial. Los autores, también otorgan a un tercero, el derecho a utilizar el articulo libremente, siempre que se mantenga su integridad y se identifique a sus autores originales, detalles de citas y editor.

El autor deberá aceptar la licencia de derechos de autor, otorgado a la revista Ciencia y Desarrollo, para el procesamiento del artículo. Todos los autores del manuscrito aceptan el contenido del mismo, y son responsables de todos los aspectos de la precisión e integridad del manuscrito. Así mismo, en consideración al criterio de originalidad, la referencia de que el articulo no ha sido publicado en otra revista.

\section{Redacción del articulo}

Los artículos, son redactados en castellano, con el título y resumen en inglés, A4 (210 x 297 mm), en una sola cara, a doble espacio, con margen de $30 \mathrm{~mm}$.

\section{Los requerimientos para la presentación de los reportes de investigación original son:}

La extensión total del manuscrito, incluyendo las referencias bibliográficas, no será mayor de 12 páginas, en una sola cara, en caracteres de 11 puntos en estilo Arial. Los manuscritos tendrán un límite de 3200 palabras (incluyendo introducción, material y métodos, resultados y discusión (se excluyen el resumen y agradecimiento); un total de 6 figuras o tablas; 40 referencias, y podrá contener hasta 250 palabras en el resumen.

Debe enviarse, sin diseñar, en formato impreso en original y digital online o en disquete, en formato Word y tablas en Excel, las figuras deben tener un mínimo de 300 de resolución. Las paginas deberán numerarse en forma consecutiva. 


\title{
La estructura de un artículo original es la siguiente:
}

\author{
Título en castellano o inglés. \\ Nombre del autor o autores. \\ Resumen que no exceda de 250 palabras y palabras clave. \\ Abstract y key words. \\ Introducción (Incluye planteamiento del problema, objetivos, hipótesis). \\ Materiales y métodos. \\ Resultados. \\ Discusión \\ Conclusión. \\ Agradecimientos (opcional). \\ Referencias. \\ Tablas y figuras. \\ Correo del autor.
}

El titulo o grado académico del autor o autores y su afiliación institucional, aparecerá en un pie de la primera página del artículo, separado del texto por una línea horizontal.

Todos los trabajos serán sometidos a revisión y evaluación por pares de la misma área, profesión y especialidad (arbitraje) con arbitraje externo ciego, previa evaluación del Comité Científico y del Comité Editorial.

\section{Pautas generales}

El título de un artículo se escribe con mayúscula inicial y minúscula, en letras cursivas, en negrita y centrado a la cabeza de la página, sin punto final. Los subtítulos de primera categoría (secciones) van marginados a la izquierda, se escriben en negrita, con mayúsculas, sin punto final. Subtítulos de segunda categoría, se marginan también a la izquierda, se escriben con mayúscula inicial y minúscula, en negrita y sin punto final. Subtítulos de tercera categoría se marginan a la izquierda, se escriben con mayúscula inicial y minúscula, en blancas, sin punto final.

Todas las unidades de medida deben ser expresadas según el Sistema Internacional de Unidades. Las cifras deben agruparse en tríos (centenas, millares, etc.) a la derecha e izquierda de la coma decimal (no punto decimal) y separadas entre sí por un espacio simple; si la cifra es de gran magnitud, la primera parte se escribe en números y luego en letras.

Las cantidades de uno al nueve se escriben en letras y de 10 en adelante en cifras, salvo los porcentajes, fracciones, edades, temperaturas, unidades de tiempo, expresiones estadísticas y divisiones de un libro.

Los títulos de las tablas van en la parte superior; las leyendas de las figuras van en la parte inferior; se escriben con mayúscula inicial y minúscula, en negrita y sin punto final.

Las tablas no llevan rayado interno vertical ni horizontal, solo tres líneas horizontales (filetes): apertura, encabezado de columnas y cierre; si hay subtítulos, utilizar líneas fraccionadas. 
Las figuras y las tablas con sus leyendas y títulos respectivos se incluirán en el texto, numeradas consecutivamente.

En el texto, las cifras se numerarán consecutivamente en orden de mención, con números arábigos en superíndice. En ese orden se colocarán en la referencia bibliográficas. Se asignará un solo número a cada referencia.

Las referencias bibliográficas seguirán el estilo Vancouver.

La cita de la primera y última página de una referencia bibliográfica debe estar completa; ejemplo: $150-163$.

Los nombres de las disciplinas científicas (medicina, odontología, etc.) y las enfermedades se escriben con minúsculas, salvo que tengan nombres propios (enfermedad de Chagas).

Los nombres genéricos de los medicamentos se escriben con minúsculas; los nombres comerciales se inician con mayúscula. Los nombres científicos se escriben en letra cursiva.

Horas del día. El punto se coloca entre la hora y los minutos (17.30 h) y se utiliza el ciclo de 24 horas. Aunque la palabra litro se abrevia con 1 minúscula, se recomienda usar L mayúscula para evitar confusión con el número 1. Las siglas se pluralizan en español con el artículo que las precede. Es incorrecto escribir el plural de las siglas a la manera inglesa: PWRs, PWR's, etc.

Tratándose del nombre oficial y el nombre abreviado institucional, primero se escribe el nombre completo y después la sigla o acrónimo entre paréntesis; ejemplo: Organización Panamericana de la Salud (OPS).

Como guía para ortografía, abreviaturas, puntuación, cifras, títulos, términos científicos, técnicos y académicos, se sugiere consultar el Manual de Estilo de cada área, además del DRAE (2001), DPD (2005) y el DSA (2005).

Para elegir las palabras clave utilizar los tesauros de cada área o profesión.

Al final del artículo figurará la dirección del autor o de uno de los autores, para fines de correspondencia.

Mientras se esté considerando para su publicación, el trabajo no podrá ser enviado a otras revistas. Una vez aprobada su publicación, los derechos de reproducción total o parcial pasarán a poder de la revista 